\title{
Assessment of the Availability and Utilization of Medicines Used for Preventing and Treating Malaria in Public Health Facilities in Jimma Town, Southwest Ethiopia
}

\author{
Hawi Wondimu and Anbessa Bekele* \\ Pharmacy School, Health Institute, Jimma University, Ethiopia
}

Submission: May 04, 2018; Published: September 11, 2018

*Corresponding author: Anbessa Bekele, Pharmacy School, Health Institute, Jimma University, Ethiopia, Tel: +251-910-817853;

Email: anbebake@gmail.com

\begin{abstract}
Malaria is one of causes of morbidity and mortality in tropical and subtropical countries. The availability, appropriate management, and rational use of medicines are critical to the successful implementation of the malaria control programs. The aim of this study was to assess the availability, use, and utilization of medicines used for preventing and treating malaria in public health facilities in Jimma town in Southwest Ethiopia. Institutional based cross-sectional study was conducted from mid of February to March 2017. Three data collection techniques were used: document reviews, structured interviews, and physical inventory checks using the World Health Organization Checklist. The most available antimalaraldrugs in health facility were Arthemeter/lumefantrine and the least one was quinine injection. On average, stock out period was $37.9 \%$, The most commonly prescribed medication was chloroquine tablet (48.09\%), followed by Arthemeter/lumefantrine combination tablet (22.9\%), chloroquine syrup (15.26\%), quinine300 mg tablet (10.68\%), and quinine injections (3.05\%) respectively. The adherence to Standard Treatment Guidelines of Ethiopia was 75\%. There was poor inventory control system and long stock out period. While most prescribers adhering to national STGs. Implementing good inventory control system, training on drug supply management, and continuous supervision of the public health facilities by Jimma town health office was recommended.
\end{abstract}

Keywords: Jimma; Anti malaria; Availability; Use and utilization of anti-malaria; Arthemeter; Pyrimethamine; Pharmaceuticals; Frequency; Malaria; Plasmodium; Disease; Population; Morbidity; Mortality; Sulfadoxine

Abbreviations: GDP: Gross Domestic Product; SP: sulfadoxine/pyrimethamine; ACT: Artemisinin- based Combination Therapy; IRS: Indoor Residual Spray; LLINs: Long Lasting Insecticidal Treat Nets; LMIS: Logistic Management Information System

\section{Introduction}

\section{Background}

Malaria remains a major global public health and development challenge. It caused 216 million cases and 655,000 deaths worldwide in 2010 , of which $81 \%$ of the cases and $91 \%$ of the deaths were from sub-Saharan Africa [1]. In Ethiopia, malaria also remains one of the most public health problems despite considerable effort made to control it [2-4]. Approximately $75 \%$ of the land mass where $68 \%$ of the total population lives is malarious [2]. The Federal democratic Republic of Ethiopia Ministry of Health estimated that there are more than 5 million clinical cases and thousands of deaths due to malaria each year [2]. However, the epidemiological pattern of the disease varies from place to place and even from time to time [5-7]. About 1 million confirmed clinical cases and 1,581 deaths were officially reported due to malaria in 2010 .
Malaria poses a significant impediment to social and economic development and the disease was responsible for the greatest economic burden upon most of the countries in the southern part of the Sahara. In 1995, the average gross domestic product (GDP) in malarias countries was five-fold lower compared to non-malaria countries [8]. The economic loss caused by malaria in Africa in 1995 was estimated at 800 million U.S dollars. By 1997 this figure has risen to USD 2 billion, an enormous health and socioeconomic burden to an already poor continent [9]. The burden of malaria has been intensified by the appearance of chloroquine-resistant plasmodium falciparum, which arouse in south East Asia and was first documented in east Africa in 1979. Since then, there have been reports of chloroquine resistance in most countries in Africa, with especially high resistance in east Africa. In addition, 
resistance to sulfadoxine/pyrimethamine (SP) is increasing. There is also growing evidence that shows the relationship between increased resistance to first line anti-malarial therapy and increases morbidity and mortality. To address this challenge the world Health Organization recommends that all countries revising their first Line treatment policies for malaria should opt for a combination treatment, preferably an artemisinin- based combination therapy (ACT) [10].

Like that of other developing countries, the most prevent health problems of Ethiopia are also communicable diseases which are preventable and treatable with essential drugs. According to the national health and health related indicators of $2005 / 6$. Malaria is a leading cause of morbidity and mortality in Ethiopia accounting for $15.5 \%$ of outpatient visit $20.4 \%$ of admissions and $27 \%$ of death in 2005/6. Malaria in Ethiopia is mainly seasonal with unstable transmissions in the high land fringe areas, while transmission in low land areas, river basins and valleys has relatively longer duration. Because of this seasonal and unstable transmission, the population lack adequate protective immunity and hence all age groups are affected. An estimated $68 \%$ of the country lands where about 51 million people live are at risk of malaria and annually about 9.4 million malaria cases are reported to access health facilities. Approximately $60 \%$ of the malaria cases are due to Plasmodium falciparum making an estimated total of 5.5 million of (PF) malaria cases in 2006 [9].

Similarly, in Jimma town the major parasite species of malaria is Plasmodium falciparum (60 \%) followed by Plasmodium Vivax (40\%). The malaria disease is among the first ten top case of Outpatient department "OPD" consultation (12 $\%$ ), the first top cause of hospitalization and inpatient deaths. Currently major ongoing activities to prevent and control the disease are vector management through indoor residual spray (IRS), long lasting Insecticidal treat nets (LLINs), parricidal application, environmental manipulation and early diagnosis and treatment of patient at all level of health facilities [10]. Therefore, continuous availability of essential drugs of proven quality, safety, efficiency and acceptability at affordable prices, compounded by rational is indispensable for rendering effective preventive and curative health services. However, the health service of the country is negatively affected by shortage and excessive wastage of drugs and medical supplies because of failure to wisely use the meager resources due to the overall poor drug supply management. The supplies of anti-malaria drugs without interruption and provision adequate chemotherapy are the key elements to roll back malaria in our nation, for the prevention and treatment of malaria.

\section{Statement of the Problem}

Effective case management for malaria requires the availability of effective anti-malarias medicines and used appropriately in the correct formulations and amounts and according to an appropriate regimen (dose, frequency, and durations). Ineffective treatment can lead to recrudescent infections, thus requiring additional treatment, which can lead to increased cost and loss of productivity, complications or death, and the development of resistance to limited anti-malarial medicines. Additional, lack of careful selection, incorrect quantification, high prices, poor quality, theft, improper storage, expiration of medicines, irrational prescribing, and patients can result in losses totaling more than 70 percent of initial acquisition costs of medicines in general [10].

Other challenges to effective case management of malaria in the health system are that the required anti-malaria medicines need is often not available. Furthermore, access to reliable and consistent information about malaria prevention and treatment of malaria require that health workers and consumers have access to a core group of medicines and supplies. Availability of these items may be influenced by a variety of factors, including poor stock control, provider experience, economic influences, cultural factors, community belief, systems and the complex interactions among these factors. A key barrier to access is affordability by the individual. Because much of the treatment seeking for malaria occurs in the private sector, the choice of strategy to be implemented may be determined by the individual's ability to pay the absolute cost of new medicine $[10,11]$.

Therefore, appropriate drug supply management, quality assurance and its management information system have a significant contribution towards the fight against these communicable diseases. Therefore, it is very important to ensure that every health unit involved in the malaria control program has an adequate supply of anti-malaria drugs and laboratory supplies and a proper way of using these supplies during the main malaria transmission period. Irregular and inadequate supplies could easily result in loss of credibility to the control program and moreover facilitate the development of program impact and more over to facilitate the development of drug resistance.

\section{Significance of the Study}

The aim of this study is to give better insight for Zonal and district departments and program managers at health facility level ability to identify high priority problem areas that might hinder the achievement of malaria prevention and control program activities and appropriate follow up the prompt treatment and early diagnosis of malaria cases and provision of appropriate anti-malaria medicine based on the National malaria treatment guidelines. More specifically The study significantly helps the pharmaceutical supply and service department of the region by providing necessary base line data's for pharmaceutical management system like proportion of expired drugs in the health facilities, the existing inventory control system or logistic management information system (LMIS) and over all utilization of anti-malarial drugs in the region to design and implement proper strategies for further implementation of improved pharmaceuticals management system in the region. The study 


\section{Global Journal of Pharmacy \& Pharmaceutical Sciences}

design is a cross-sectional descriptive survey to establish the baseline for monitoring of future interventions.

\section{Literature Review}

Drug utilization study of anti-malarias for the treatment of hospitalized children under five in south-eastern Nigeria carried out by obinnalkechukwu Ekwunife described the trend in the use of anti-malarias for the treatment of malaria in children under 5 years from year 2000 to 2006 in south-eastern Nigeria was assessed adherence to the 2005 National Anti-malarial Treatment Policy [12]. Quality indices studies were the use of international nonproprietary name (INN) in prescription, number ofanti-malarias per episode and use of drugs from essential drug list [12]. The study concluded that there was a need for further studies to establish factors that affect the dissemination and use of treatment guidelines in Nigeria.

A cross sectional study of 630 randomly selected rural households carried out by Wakgari et al. [13] in 6 peasant associations of Butajira District in southern Ethiopia assessed the knowledge ,attitudes and practices of rural community on malaria mosquito vector and anti-malaria drugs .The study finding reveled that Fever, headaches, chills and shivering were the most frequently mentioned symptoms of malaria transmission to the bite of infective mosquitoes and $43 \%$ of them believed that malaria can be transmitted from person to person through the bite of mosquitoes. Mosquitoes are mainly believed to bite human beings at night (73.2\%), breed in stagnant water (71\%) and rest in dark places inside houses during daytime (44.3\%). Malaria was thought to be preventable by $85.7 \%$ of the respondents. Most of the respondents, $62.4 \%$ reported chemoprophylaxis,39.6\% indicated that indoor residual spraying and $25 \%$ mentioned eliminating breeding sites as preventive methods. The use of modern drugs for malaria was high (92\%) including chloroquine $(73.5 \%)$ and sulfadoxinepyremethamine (60.6\%). chloroquine was believed to be effective for the treatment of malaria by $59 \%$ of the respondent, while the remaining replied that it was ineffective. About four hundred two $(63.8 \%)$ respondents reported sulfadoxinepyremethamine to be the most effective anti-malaria drug for the treatment of malaria in contrast to others [13]. The finding of study concluded that the study subjects are familiar with the symptoms of malaria and to a lesser degree, are aware of an association between mosquito and malaria. Health workers at different levels of the health care delivery system should disseminate relevant information about malaria to help community member to be involved more in malaria control [13].

A study conducted by HansVerhoef, Elsa Hodgins, Teunis [14]. In Kenya to estimate the proportion of asymptomatic Kenyan preschool children using anti-malarial drugs, identified factors associated with chloroquine use, and assessed the validity of frequency of febrile episode and drug use reported by mothers or careers. Out of 318 children studied,38\% (with $95 \%$ confidence interval $530-47 \%$ ) tested positive for chloroquine or sulfadoxine. According to the result of the finding for chloroquinepositive children, $15 \%$ of them had contraindications exceeding the estimated minimum therapeutically effective values. Among those testing negative for sulfadoxine, chloroquine-positive children were more frequently parasitemia (odds ratio 5 2.6, with $95 \%$ confidence interval 5 1.3-5.2), and had lower mean hemoglobin concentrations $(6.1 \mathrm{~g} / \mathrm{L}$, with $95 \%$ confidence interval 5 2.1-10.1) than chloroquine- negative children. Mothers over-reported the frequency of malaria or fever episodes as usually defined in medical studies, and an reported anti-malaria drug use. The study concludes that anti malaria is frequently given for treatment of malaria or malaria associated illness, rather than prophylactic ally or for symptoms unrelated to malaria Questionnaire survey cannot replace biochemical markers to obtain information on anti-malaria drug use [14].

A survey conducted by Philippe Minodier, Assimouna Nassur, and Sophie assessed anti-mosquito Precautions and Medical Chemoprophylaxis in French Children with Malaria in Eighty-eight children under 15 years of age for the 3-month Period. According to the result of this finding, less than average compliance with coetaneous repellents, bedroom repellents and long-sleeved clothing were $32 \%, 24 \%$ and $26 \%$, respectively. Air conditioners were uncommon for the study. From the study participants only $22 \%$ of the children used chemoprophylaxis correctly, five percent did not use any chemoprophylaxis, and 61\% reported non-recommended drug use. Although all the children travelled to chloroquine resistant areas, chemoprophylaxis with mefloquine was less common than that with chloroquine + proguanil No child fully complied with French recommendations concerning both ant mosquito measures and prophylaxis [15]. As a result most of them had been infected in Comoro archipelago. The researchers concluded that insufficient use of anti-malaria precaution by traveling families is associated with the high incidence of pediatric imported malaria in southern France. Travelers' education should be increased to allow the optimization of malaria prophylaxis [15]. falciparum malaria is the prime target for chemoprophylaxis to prevent death and severe disease. Although we considered doing a separate risk analysis for this species, reporting at the species level in the first year of the study was not sufficiently complete to allow for meaningful analysis. Furthermore, other malaria species also contribute substantially to malaria illness in travelers [16]. Falciparum malaria is a clinically overt disease and will most probably be diagnosed. For other malaria species, a few cases, especially in persons with partial immunity, might be missed, thus underestimating the true risk.

A study done on 142 partisans on use of medical chemoprophylaxis and Anti mosquito precautions in Danish Malaria patients and their traveling companions by ingolfMolle, Kent L.Christensen, described the use of chemoprophylaxis and anti-mosquito precautions in Danish malaria patients and their traveling companions, and evaluated the role of side effects from chemoprophylaxis with respect to compliance and 
the prescription and use of appropriate drugs with respect to Danish official Danish. The study results reveled that only $32 \%$ of the travelers did not use chemoprophylaxis. About average compliance was $52 \%$. Also, in sufficient drug dosage was reported by $13 \%$ and use of non-recommended drugs reported by $7 \%$ of the travelers about $37 \%$ of the participants used insufficient antimosquito precautions, these problems which often coincided with irregular use of chemoprophylaxis. Malaria patients, sole travelers, and travelers with other ethnical background than Danish Were subgroups using insufficient malaria prophylaxis more frequently than healthy traveling companions and they concluded that insufficient use of the available anti malaria precautions by Danish travelers contributes greatly to maintaining a high incidence of imported malaria. The study recommends due attention from physicians in educating travelers is important for optimizing malaria prophylaxis [17].

A threshold analysis of the cost effectiveness of artemesinebased combination therapies in sub Saharan African done showed that Artemisinin-based combination therapies (ACTs) more than $95 \%$ likely to be cost-effective under most conditions, other than very low levels of initial resistance to sulfadoxine/ pyrimethamine and five-year time frame. These predictions are conservative in the $95 \%$ certainty is a stringent decision rule favoring the rejections of new policies. The importances of other variables not included in the analysis for the robustness of the findings were discussed (e.g., consideration of the growth of resistance modeled according to population genetic parameters. Another descriptive study conducted in Ghana assessed the feasibility, acceptability and the willingness to use Artemetherlumefantrine (coartem) during early, appropriate treatment of Malaria/fever in children aged 6-59 months at the community and household level in rural malaria-endemic area in Ghana. The investigator concluded that Home Management of Malaria (HMM) strategy with coartem using trained communitybased agents supervised monthly is feasible, acceptable and achieved high level of compliance within Dangme, West district of Ghana. However, as the intervention is to be sustainable, the agents need to be paid [18].

A study carried out assessed (IPT) drugs given to prevent malaria infection and its consequences in pregnant women living in malaria areas. This study included prophylaxis and intermittent preventive treatment (IPT) showed that. Chemoprophylaxis or IPT reduces antenatal parasite prevalence and placental malaria when given to women in all parity groups. They also have positive effects on birth weight and possibly on prenatal death in low parity women [19].

\section{Objectives}

\section{General Objective}

To assess the availability of medicines used for preventing and treating malaria in public health facilities at Jimma town.

\section{Specific objectives}

a. To review prescribing and dispensing practice for malaria cases in selected health facility in Jimma town.

b. To calculate average percentages of a set of unexpired drugs in selected Health Facilities and identify time of stock out for set of anti-malaria drugs at HFs.

c. To determine the availability of anti-malarial medicines required for treating and preventing malaria in Jimma town.

d. To measure the percentage of patients diagnosed with uncomplicated malaria in which they are prescribed with appropriate quantities of anti-malarial drugs sufficient to complete a full course of treatment.

\section{Methodology}

\section{Study Area and Period}

The study area was in Jimma town which is in south west part of Oromia region at $365 \mathrm{Km}$ from the capital of Ethiopia. This Study was carried out from mid of February to March 2017 at selected Public health facilities that were involved in malaria treatment activities at various levels during the routine health activities including emergency services. There were three primary health care units, one zone hospital and one referral and specialized hospital located in Jimma town from this higher two, menderakochi and jimma health center and shanan gibe hospital were selected. In addition to the public health facilities there were also various private health facilities in the town. However, the current study was focused only on the government public owned health facilities.

\section{Study Design}

Indicator based cross sectional study was conducted on selected public facilities.

\section{Data Source}

Public health facilities document review, observation of facility health professionals during examination and treatment of cases of malaria and physical inventory checks.

\section{Population}

i. Source population: All public health facilities located in the Jimma town were the source population.

ii. Study population: All out patients with malaria cases visiting health facilities in Jimma town.

\section{Sample Size}

There were 5 governmental public health facility in Jimma town from this four-health facility were selected on purpose, for assessing (evaluating)drug used from recorded data 3 prescriptions of malaria cases per day for the last 1 month will be selected from each HFs $(\mathrm{N}=336)$.

\section{Sampling Techniques}

Almost all the governmental health facility in Jimma town 
was selected and from all drug prescriptions Antimalaria drug prescription was picked.

\section{Data Collection Instruments}

Data will be collected using structured and modified USAID/ MSH drug use and drug assessment indicators checklists.

\section{Data Collection Techniques}

Three data collection techniques were used: document reviews, observational of Health workers, and physical inventory checks using USAID/MSH drug use availability assessment indicator.

\section{Inclusion criteria}

a. Governmental health facility.

b. Those health facilities where more than five cases of malaria can be expected per day.

\section{Exclusion criteria}

a. Nongovernmental health facility.

b. New health facility.

\section{Variables}

\section{Dependent Variable}

Availability and utilization of antimalarial drugs in PHFs.

\section{Independent Variable}

a. Cost of drugs

b. Pattern of stock recording of HFs

c. Availability of national STGs

d. Amount of anti-malarial drugs expired

e. Stock out period.

\section{Data Processing and Analysis}

The collected data were cleared, categorized, and coded accordingly Data were presented using frequency tables
Descriptive statistics such as mean, frequencies, and percentages were used to describe and summarize the data.

\section{Data Quality Measures}

Data collected from all the survey facilities using the standard data collection forms were coded, checked for accuracy, consistency, omissions and irregularities. they were then entered in to Microsoft excel 2010 and summarized using the standard summary forms, All the required statistical analysis was done using excel 2010.

\section{Ethical Consideration}

The official support letter was written from Jimma university department of pharmacy to Jimma town health office then the health office writes the support letter to each health center for the data collection All concerned officials at all levels were communicated to and informed about the purpose of the study, and assured confidentiality of the response and informed consent was obtained from the managers of each public health facility. Participation on the study was on a voluntary basis. The rights of the managers of the facility were respected.

\section{Limitation of the Study}

Some of the data were not complete and insufficient because of poor record keeping system of health facilities and this made the research done with less sample size than calculated. And unavailability of some related literature data on the topics.

Result

\section{Anti-Malaria Drug Availability}

Regarding the availability of Standard Treatment Guidelines (STGs) of Ethiopia in health facilities, the availability of two guidelines, namely, malaria diagnosis and treatment guidelines for health workers in Ethiopia and standard treatment guidelines for health centers, were selected as a criterion. About $75 \%$ of visited health facilities had a copy of STGs. About $77 \%$ of patients/caregivers were able to correctly describe how to take/ give the prescribed antimalarial medicine (Table 1).

Table 1: The table summarizes the Jimma town score on drug utilization compared to national target for the mentioned antimalarial drugs.

\begin{tabular}{|c|c|c|c|c|}
\hline Name of Indicator & National Target & Ideal Value & Result (\%) & no \\
\hline \multicolumn{5}{|l|}{ Percentage of public health facilities visited } \\
\hline \multicolumn{5}{|l|}{ that had a copy of the official treatment } \\
\hline Guidelines for malaria. & 100 & 100 & 75 & 3 \\
\hline $\begin{array}{l}\text { Percentage of encounters with patients diagnosed with uncomplicated malaria that are } \\
\text { prescribed antimalarial drugs consistent with treatment guidelines. }\end{array}$ & 90 & 100 & 77 & 92 \\
\hline Percentage of prescribed antimalarial medicines dispensed by public health facilities & 100 & 100 & 83.3 & 109 \\
\hline $\begin{array}{l}\text { Percentage of encounter with patients diagnosed with uncomplicated malaria who are } \\
\text { prescribed quantities of appropriate anti malarias enough to complete a full course of } \\
\text { treatment }\end{array}$ & 90 & 100 & 90 & 118 \\
\hline
\end{tabular}

N.B. the source for the national target and the zonal target values were adopted from national health sector development program III. Third phase from year 2005-2009 E.C. federal ministry of health Ethiopia and jimma town health sector development program III from 2005-2009 E.C. jimma town health bureau. Targets are assumed to be achieved at the end of 2009 E.C. The availability of three antimalaria drugs (Artemether/lumefantrine, chloroquine, and quinine) in 6 different preparations that are used to treat uncomplicated malaria at different facility of Jimma town were selected from 
national drug list (NDL) of Ethiopia, and the availability of these drugs was assessed at 4 health facilities. Quinine IV injection was the least available drug in the facilities (20\%) and Artemether/ lumefantrine $120 \mathrm{mg} / 20 \mathrm{mg}$ combination tablet was the highest available drug in the health facilities (100\%).

Stock out duration of 3 month was then calculated at each facility level using the standard formula. The average stock out duration in PHFs was 51days. Average stock out duration by level of health care facilities were 30 days, 45 days, 50 days and 80 days in hospitals $(n=1)$ health centers $(n=3)$ respectively. The following figure shows the average stock out durations by level of health facilities. And Shanan Gibe hospital is with the lowest stock out day 30 (Figure 1).

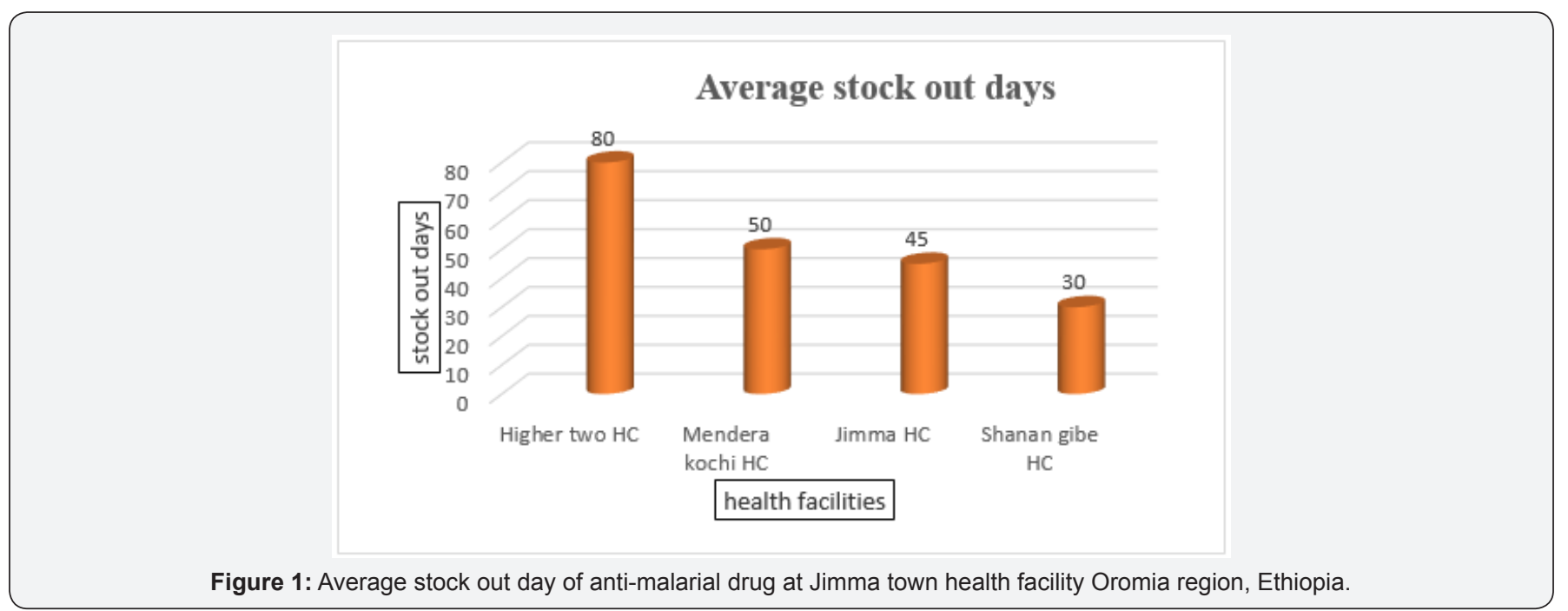

To measure the availability of antimalarial drugs to treat malaria problems, a retrospective survey was under taken by reviewing the facilities documents covering a period of 1 month. The number of days for which each antimalarial drug was not available within the review period was recorded in the then calculated at each facility level using the standard formula. The Jimma town health facility stock out period was $37.9 \%$. The average percentage of stock records that corresponds to with physical counts for set of PMM. An antimalarial medicine in public health facility of Jimma town is $41.6 \%$ (Table 2 ). standard survey format. The average stock out duration was Table 2: Drug availability at the studied facilities compared with the national target.

\begin{tabular}{|c|c|c|c|c|}
\hline No & Indicator name & National targets (\%) & Ideal value & Result (\%) \\
\hline 1 & $\begin{array}{c}\text { Average Percentage of a set of unexpired PMM anti malaria medicines } \\
\text { available in health facilities }\end{array}$ & $65-100$ & 100 & $63 \%$ \\
\hline 2 & $\begin{array}{c}\text { Average percentage of time out of stock for a set of PMM antimalarial } \\
\text { medicines in health facilities }\end{array}$ & $35-0$ & 0 & $37.9 \%$ \\
\hline 3 & $\begin{array}{c}\text { Average Percentage of stock records that correspond with physical counts for } \\
\text { a set of PMM anti-malarial medicines in health facilities. }\end{array}$ & $8.24-2$ & 0 & $41.6 \%$ \\
\hline
\end{tabular}

\begin{tabular}{|l|l|l|l|}
\hline \multicolumn{2}{|c|}{ PERCENTAGE OF AVAILIBLITY OF } \\
EXPIRED DRUG \\
\hline
\end{tabular}




\section{Global Journal of Pharmacy \& Pharmaceutical Sciences}

The existing inventory control systems of the health facility was using a manual by using bin card and stock card method there were poor inventory control system in Jimma town health facility there were no computerized inventory control system. The presence of expired antimalarial drugs at facility level was assessed to determine if expired drugs are being physically available, distributed or sold as one indicator of good pharmaceutical management system for malaria drugs. The actual process involved checking the expired drugs were then calculated at facility level and regional level.

The Zonal average Percentage availability of expired drugs was $37 \%$. When compared by level of Health Facilities. At four Health Facilities percentage of availability of expired drugs were assessed based on this at Jimma HC 40\%, Manderakochi HC 50\%, higher 2 HC $33 \%$ and $25 \%$ in Shanan gibe hospital $\%$ in health centers $(n=1)$ and hospital $(n=3)$ respectively (Figure 2).

\section{Antimalarial Drugs Utilization}

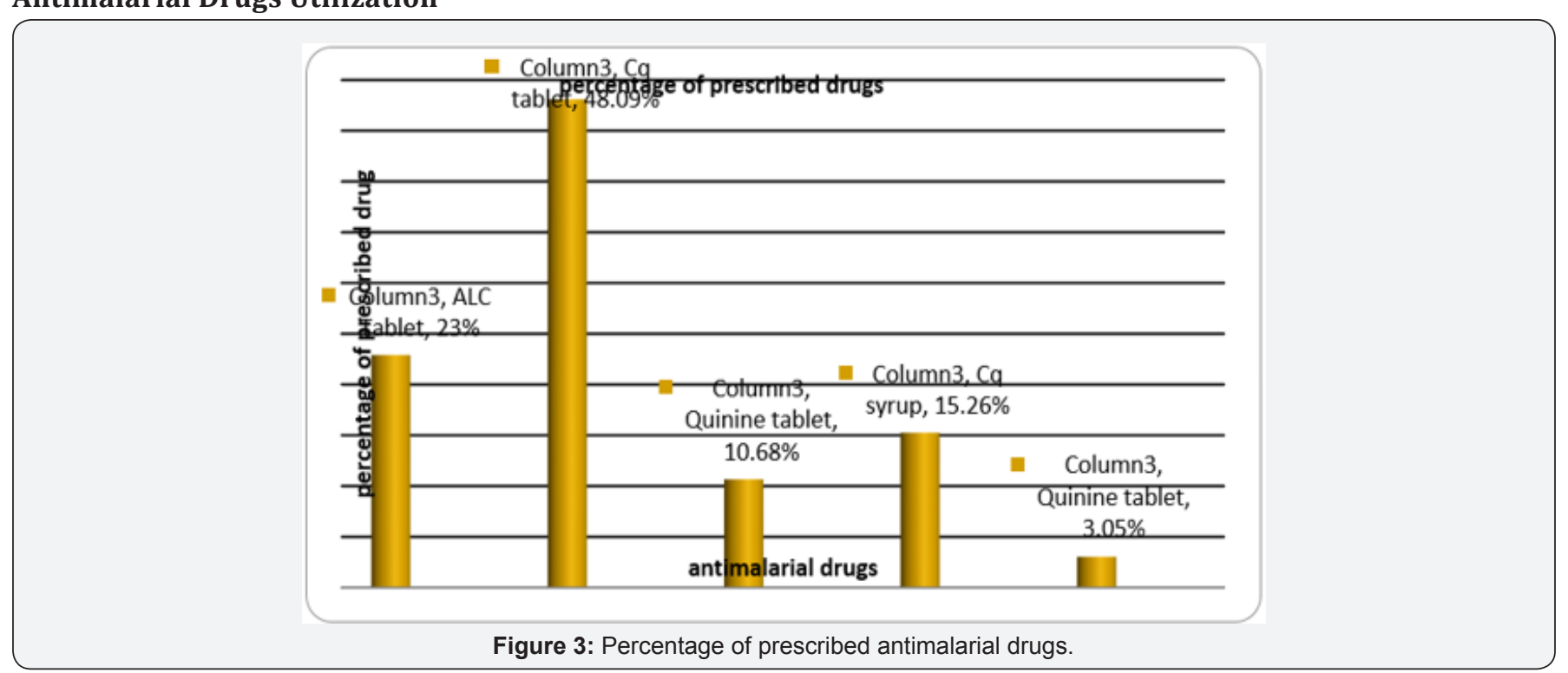

Table 3: Drug availability at the studied facilities compared with the national target.

\begin{tabular}{|c|c|c|c|}
\hline s.no & Drug product & $\begin{array}{c}\text { Number of } \\
\text { patients(n) }\end{array}$ & Result \% \\
\hline 1 & $\begin{array}{c}\text { Chloroquine phosphate } \\
150 \mathrm{mg} \mathrm{tab}\end{array}$ & 63 & $48.09 \%$ \\
\hline 2 & $\begin{array}{c}\text { Quinine } 300 \mathrm{mg} / \mathrm{ml} \\
\text { injection }\end{array}$ & 4 & $3.05 \%$ \\
\hline 3 & $\begin{array}{c}\text { Chloroquine injection } \\
\text { mg/ml 5 ml vial* }\end{array}$ & 0 & 15.26 \\
\hline 4 & $\begin{array}{c}\text { Chloroquine syrup 50 } \\
\text { mg/5 ml }\end{array}$ & 14 & $10.68 \%$ \\
\hline 5 & Quinine 300 mg tablet & 30 & $22.9 \%$ \\
\hline 6 & $\begin{array}{c}\text { Artemether/ lumefantrine } \\
20 \mathrm{mg} / 120 \mathrm{mg} \text { tablet }\end{array}$ & 14 & 0 \\
\hline
\end{tabular}

To assess the prescribing and dispensing practices for managing uncomplicated malaria cases a total of 131 malaria specific prescription papers and patient registration books were reviewed from four health facilities and a total of 10 malaria case management of health workers were observed to investigate the clinical assessment of health workers. Of 131 uncomplicated malaria cases assessed by reviewing recording books on average $59 \%$ were males and $41 \%$ females of the total cases investigated. The average percentage of encounters with patients diagnosed with malaria that were prescribed antimalaria drugs consistent with treatment guidelines was $75 \%$. The most commonly prescribed medication was chloroquine $150 \mathrm{mg}$ tablet combination tablet (48\%), followed by Artmether/lumefanirrine $120 / 20 \mathrm{mg}$ tablet (22.9\%), chloroquine syrup (15.26\%), quinine $300 \mathrm{mg}$ tablet $(10.6 \%)$ and artesunate injections (3.5\%). This result is listed below in (Table 3) and (Figure 3).

The average percentage of encounter with uncomplicated malaria who were prescribed quantities of appropriate antimalarious sufficient to complete a full courses treatment was $90 \%$.average cost Regarding the availability of STGs in health facilities the physical availability of Two guidelines namely malaria diagnosis and treatment guidelines for health workers in Ethiopian second edition 2004 G.C prepared by ministry of health $(\mathrm{MOH})$ and standard treatment guidelines for health centers, health posts, district and zonal hospitals prepared by drug administration and control authority (FMHACA) were selected as a criteria About $75 \%$ of visited health facilities had a copy of STGs. Percentage of patients/caregivers who correctly describe how to take/give the prescribed antimalarial medicine was found to be $83 \%$.

\section{Discussion}

This study revealed that the prescribing and dispensing practices for managing uncomplicated malaria cases, of which a total of 130 malaria specific presentation papers and patient registration books were reviewed. Based on this study there was acceptable availability of antimalarial drugs in public health facilities of Jimma town, but it is still below the estimated target, 
which was set at national level [19]. The federal ministry of health has received donations from Global Fund and the Roll Back African project to increase the availability of Artemether/ lumefantrine combination drugs free of charge in governmentowned health facilities and to implement the new approaches to the eradication of malaria. The low level of target achievement of Jimma town was probably due to low logistics management information system reporting rate of health facilities to Ministry of Health (MOH) and Zonal Health Bureaus (ZHBs). The delay in release of allocated budget to the fiscal year can also contribute to the delay of procurement of pharmaceuticals, which can ultimately affect the availability of drugs [20].

A research done in the republic of Iran to evaluate availability of drugs in 100 primary health care centers showed that on average, $92 \%$ of the 12 essential drugs monitored were available in the health center pharmacies [21]. A similar study done in Sudan to evaluate availability of essential drugs in 36 public health facilities found that on average, $82 \%$ of the core medicines monitored were available in the centers [22]. The difference in the availability of the two studies is probably due to small study size of this study and relatively low health care cost expenditure of Ethiopia compared to others.

The finding showed that there is a long stock out period of antimalaria drugs (37.9\%); but the Jimma zonal average stock out duration in public health facilities s was 51days. This figure is greater than ideal value and the expected national target to be achieved at the end of year 2015 (35\% to 0\%), [23] and to that of a research done in Iran, [24] with the stock out duration of less than 1 month on average. This might be due to poor pharmaceutical logistics system, which was proved by the presence of many expired drugs and poor inventory control system in the public health facilities.

The present study revealed that the average percentage of prescribers' adherence to national treatment guideline for this study was $75 \%$ of patients. This is higher than other studies done in Sudan [25] which reported adherence to national treatment guidelines ranging from $38.6 \%$ to $64 \%$. The relatively high level of adherence to STGs of this study compared to the Sudan study is probably due to small sample size of this study and poor implementation of national drug policy in Sudan.

In this study, the average percentage of drugs encounter with antimalaria that was prescribed enough quantities to complete a full courses treatment was $90 \%$. This indicator measures the extent to which malaria patients/caregivers are prescribed enough medicines by the public health facility to complete a full course of treatment. A full course of treatment is based on the description given on standard treatment guidelines for Ethiopia. For instance, for Artemether/lumefantrine combination tablets, a full course for an adult would normally be 4 tablets 2 times a day for 3 days. The total number of tablets required for the course of treatment is 24 Artemether/lumefantrine combination tablets of $120 \mathrm{mg} / 20 \mathrm{mg}$ each. Regarding the availability of
STGs, ideally all health facilities should have a copy of STGs but in the present study only about $75 \%$ of visited health facilities had a copy of STGs. The ministry of health had prepared and distributed several standard treatment guidelines for various disease conditions. The Ethiopian Food, Medicine, and Health Care Administration Control Authority (FMHACA) has also prepared standard treatment guidelines for different levels of health facilities in 2004 (revised in 2010) and distributed to every regional health bureaus.

In the current study, $83.3 \%$ of prescribed antimalaria drugs were dispensed by public health facilities. This indicator is based only on the prescriptions for antimalaria drugs presented for dispensing at public health facilities. Other studies reported the finding in the range of $85 \%$ to $95 \%[19,20]$ Three-fourths of patients/caregivers correctly describe how to take/give the prescribed antimalaria medicines. This indicator measures if patients have adequate knowledge on how to take the drugs dispensed to them. Knowledge about the drug constitutes ability to tell dose, frequency of administration, and length of therapy fully. This figure is in line with national target (68\%-100\%).

\section{Conclusion}

Overall availability of antimalarial drugs in the jimma town health facility was acceptable though there were poor inventory control systems, record keeping system and a long stock out period of antimalaria drugs in public health facilities of the Jimma town. There was a practice of good dispensing. The knowledge of many patients or caregivers about dispensed drugs was also good. Most prescribers adhere to STGs of Ethiopia country when prescribing antimalaria drugs.

\section{Recommendation}

Table 4: List and Distribution of health facilities assessed.

\begin{tabular}{|c|c|c|c|}
\hline S. no & Name of health facility & Level of HFs & $\begin{array}{c}\text { Location/ } \\
\text { district/ }\end{array}$ \\
\hline 1 & Shanan gibe hospital & Zone hospital & Bocho bore \\
\hline 2 & Jimma health center & Health center & Ferenjearada \\
\hline 3 & Higher two health center & Health center & merkato \\
\hline 4 & Menderakochi health center & Health center & kochi \\
\hline
\end{tabular}

Based on this study finding my recommendation goes to the responsible stake Holders first

a. To Jimma zone health bureau should implementing a good inventory control system, training on drug supply management, and continuous supervision of the public health facilities.

b. Systematizing and modernizing of drug supply and management system through use of appropriate software and providing necessary instruments and tools to ensure proper management and use of drugs at health facilities.

c. The reporting system of health facilities need to be strengthened. 
d. Developing zonal pharmaceutical plan of action; guideline for good prescribing and dispensing practice and zonal medical supplies and equipment's list and ensuring their application through training, adequate dissemination and supervision is necessary (Table 4).

\section{Acknowledgement}

The authors' heartfelt thanks go to Jimma University, Institute of Health Sciences for facilitating this research. We also thank Jimma town health office staffs and all staff of four health facility of Jimma town for their cooperation for our work.

\section{References}

1. WHO: World malaria report (2011) World Health Organization, Geneva, Switzerland, Europe.

2. Federal democratic Republic of Ethiopia Ministry of Health: Ethiopia National Malaria Indicator Survey (2011) Technical Summary. Ministry of Health of Ethiopia, Ethiopia.

3. Degarege A, Animut A, Legesse M, Erko B (2009) Malaria severity status in patients with soil-transmitted helminth infections. Acta Trop, Ethiopia.

4. Degarege A, Legesse M, Girmay M, Animut A, Erko B (2012) Malaria and related outcomes in patients with intestinal helminths: A crosssectional study. BMC Infect Dis, Ethiopia. 9: 12.

5. Deressa W, Ali A, Berhane Y (2006) Review of the interplay between population dynamics and malaria transmission in Ethiopia. Ethiop J Health Dev 20(3): 137-144.

6. Woyessa A, Deressa W, Ali A, Lindtjørn B (2012) Prevalence of malaria infection in Butajira area, south-central Ethiopia. Malar J, Ethiopia.

7. Graves P, Richards FO, Ngondi J, Emerson PM, Shargie EB, et al. (2009) Individual, household and environmental risk factors for malaria infection in Amhara, Oromia and SNNP regions of Ethiopia. Trans R Soc Trop Med Hyg, Ethiopia.

8. Assessment and monitoring of antimalarial drug efficacy for the treatment of uncomplicated falciparum malaria (2003) World Health Organization, Geneva, Switzerland, Europe.

9. National health \& health related indicator of Ethiopia (2005) FMOH, Ethiopia.

10. Pharmaceutical management for malaria guideline by MSH/ USAID/2004 edition

11. Federal democratic Republic of Ethiopia Ministry of Health: Ethiopia National Malaria Indicator Survey (2011) Technical Summary. Ministry of Health of Ethiopia, Ethiopia.
12. Chinwe Victoria Ukwe (2006) Drug utilisation study of antimalarial for the treatment of hospitalized children under five in south-eastern Nigeria.

13. Deressa W, Ali A, Berhane Y (2006) Review of the interplay between population dynamics and malaria transmission in Ethiopia. Ethiop J Health Dev 20(3): 137-144.

14. Hans Verhoef, Elsa Hodgins, Teunis (1999) antimalarial drugs use among preschool children in an area of seasonal malaria in Kenya, Africa.

15. Philippe Minodier, Assimouna Nassur, sophie Antimosquito (2001) Precautions and Medical Chemoprophylaxis in French children with malaria.

16. Rowe AK, Rowe SY, Snow RW, Korenromp EL, Schellenberg JR, et al (2006) The burden of malaria mortality among African children in the year. Int J Epidemiol 35: 691-704.

17. Ingolf Molle Kent L (1999) Christensen of medical chemoprophylaxis and Antimosquito precaution in Danish Malaria patients and their Traveling CXompanions.

18. Amanua M, Chinbuah1, John O Gyapong (2006) Feasibility and acceptability of the use of artemethrlumafantrine in the home management of uncomplicated malaria in children 6-59 months old in Ghana, Africa.

19. Federal Ministry of Health of Ethiopia. Health Sector Strategic Plan (HSDP-III) (2005) Addis Ababa: Planning and Programming Department, Ethiopia.

20. Center for Disease Control (2011) Malaria Operational Plan has been endorsed by the U.S. Global Malaria Coordinator and reflects collaborative discussions with the national malaria control programs and Partners in Ethiopia. Atlanta, Ethiopia.

21. Cheraghali AM, Nikfar S, Behmanesh Y (2004) Evaluation of availability, accessibility and prescribing pattern of medicines in the Islamic Republic of Iran. EasMediter Health J 10(3): 406-415.

22. Cheraghali AM, Idries AM (2009) Availability, affordability, and prescribing pattern of medicines in Sudan. Pharm World Sci 31(2): 209-215.

23. Federal Ministry of Health of Ethiopia. Health Sector Strategic Plan (HSDP-III) (2005) Addis Ababa: Planning and Programming Department, Ethiopia.

24. Cheraghali AM, Nikfar S, Behmanesh Y (2004) Evaluation of availability, accessibility and prescribing pattern of medicines in the Islamic Republic of Iran. Eas Mediter Health J 10(3):406-415.

25. Mannan AA, Malik EM, Ali KM (2009) Antimalarial prescribing and dispensing practices in health centres of Khartoum state. East Mediter Health J 15(1):122-128.

Your next submission with Juniper Publishers
will reach you the below assets
- Quality Editorial service
- Swift Peer Review
- Reprints availability
- E-prints Service
- Manuscript Podcast for convenient understanding
- Global attainment for your research
- Manuscript accessibility in different formats
( Pdf, E-pub, Full Text, Audio)
- Unceasing customer service
Track the below URL for one-step submission
https://juniperpublishers.com/online-submission.php

